\title{
PROCJENA ZADOVOLJSTVA OPERIRANIH GINEKOLOŠKIH PACIJENTICA ZDRAVSTVENOM SKRBI U SVEUČILIŠNOJ KLINIČKOJ BOLNICI MOSTAR
}

\author{
Albert Haller ${ }^{1}$, Adriana Haller ${ }^{1}$, Vajdana Tomić ${ }^{1},{ }^{2},{ }^{3}$ \\ ${ }^{1}$ Medicinski fakultet Sveučilišta u Mostaru \\ ${ }^{2}$ Klinika za ginekologiju i porodništvo, Sveučilišna klinička bolnica Mostar \\ ${ }^{3}$ Fakultet zdravstvenih studija Sveučilišta u Mostaru \\ Bijeli brijeg b. b. 88000 Mostar, Bosna i Hercegovina
}

Rad je primljen 25.01.2021. Rad je recenziran 16.02.2021. Rad je prihvaćen 19.02.2021.

\section{SAŽETAK}

Uvod: Kvaliteta zdravstvene skrbi se danas mjeri pomoću dva parametra, zdravstvenim ishodima pacijenata i njihovim zadovoljstvom.

Cilj: Cilj ovog istraživanja bio je ispitati razinu zadovoljstva zdravstvenom skrbi operiranih ginekoloških pacijentica.

Metode: Presječno istraživanje zadovoljstva pacijenata provedeno je u Odjelu ginekologije Klinike za ginekologiju i porodništvo Sveučilišne Kliničke bolnice Mostar anonimnim anketiranjem pomoću upitnika koji je dizajniran isključivo za ovo istraživanje. U istraživanje je uključeno ukupno100 pacijentica koje su bile podvrgnute ginekološkom operacijskom zahvatu.

Rezultati: Prosječnim ocjenama preko 4, 5 ocjenjene su sve kategorije u predoperacijskom i postoperacijskom dijelu Odjela ginekologije uključujući komunikaciju sa ginekolozima, anesteziolozima i medicinskim sestrama. Ispitivana skupina imala je relativno kratku hospitalizaciju s prosjekom zadržavanja u bolnici od 4, 6 dana. Više od 70 \% pacijentica je bilo hospitalizirano do 6 dana. Urednost i čistoća prostora je ocjenjena visokom prosječnom ocjenom 4, 6; a odnos pomoćnog osoblja je na visokoj razini (prosječna ocjena 4,8 ).

Zaključak: Visoke ocjene zadovoljstva pacijentica predstavljaju obvezu nastavka njegovanja komunikacijskih vještina ukupnog medicinskog i nemedicinskog osoblja. Provedeno istraživanje predstavljati će polaznu osnovu za provođenje daljnjih istraživanja o zadovoljstvu pacijentica u Odjelu ginekologije.

Ključne riječi: zadovoljstvo pacijentica, zdravstvena skrb, ginekologija, SKB Mostar

\section{Kontakt osoba:}

Prof. dr. sc. Vajdana Tomić, dr. med.

E-mail:vajdana. tomic@fzs.sum.ba 


\section{UVOD}

Kvaliteta zdravstvene skrbi se danas mjeri pomoću dva parametra, zdravstvenim ishodima pacijenata $\mathrm{i}$ njihovim zadovoljstvom. Zadovoljan pacijent jedan je od glavnih pozitivnih pokazatelja kvalitete zdravstvene skrbi svake zdravstvene ustanove (1). Stoga, neprekidno poboljšanje mjera kvalitete zdravstvene skrbi i traženja načina da se pruži što bolja medicinska usluga s pozitivnom percepcijom i doživljajem pacijenata predstavlja imperativ suvremene medicine. Zadovoljstvo pacijenata ima izrazito važnu ulogu u holističkim aspektima ozdravljenja i emocionalne dobrobiti (2). Bolnice koje imaju bolju komunikaciju i suradnju s pacijentima mogu potaknuti kvalitetnije prihvaćanje kliničkih standarda dijagnostike i protokola liječenja, a kod pacijenata koji su zadovoljniji uslugom postoji veća vjerojatnost da će pažljivije slijediti preporuke kliničara (3). U ovom radu provedeno je istraživanje zadovoljstva ginekoloških pacijentica podvrgnutih operativnom zahvatu u Sveučilišnoj kliničkoj bolnici Mostar (SKB Mostar). Glavni cilj rada bio je ispitati zadovoljstvo pacijenata dobivenom predoperacijskom i postoperacijskom medicinskom skrbi u ginekološkom odjelu SKB Mostar. Konačni cilj je pronaći područja za poboljšanje kako bi se povećalo zadovoljstvo ginekoloških pacijentica i na taj način poboljšala kvaliteta medicinske skrbi u ginekološkom odjelu SKB Mostar.

\section{ISPITANICI I METODE RADA}

U istraživanje je uključeno 100 pacijentica koje su bile podvrgnute operacijskom zahvatu zbog bolesti ženskih spolnih organa. U metodama istraživanja primijenjena je anonimna anketa pomoću upitnika posebno dizajniranog za ovo istraživanje. Uz pitanja o općim i sociodemografskim podatcima, ispitanice su popunjavale upitnik o zadovoljstvu dobivenom skrbi koji se sastoji od pet skupina pitanja, a koja su ocjenjena ocjenama: 1 - jako loše, 2 - loše, 3 - dobro, 4 - vrlo dobro ili 5 - izvrsno. Prva skupina pitanja se odnosi na iskustvo u predoperacijskom dijelu Odjela uključujući i operacijsku salu, a druga skupina na iskustvo i zadovoljstvo zdravstvenom skrbi u postoperacijskom dijelu Odjela. Pitanja se odnose na zadovoljstvo interakcijom sa svim zdravstvenim dje- latnicima koji dolaze u kontakt s ispitanicom. Treća skupina pitanja se odnosi na zadovoljstvo higijenom prostora u kojem su ispitanice boravile, kvalitetom prehrane koju su dobivale i odnosom pomoćnog osoblja. Četvrta skupina pitanja ocjenjuje ukupni doživljaj medicinskog osoblja. U petoj skupini upitnik sadrži pitanja koja ocjenjuju ukupnu kvalitetu boravka na Odjelu.

Statistička obrada rezultata je obavljena u Microsoft Excel-u. Analiza frekvencija je učinjena pomoću Hi-kvadrat testa, analiza intervalne skale ocjenjena je primjenomneparametrijskog testa (Wilcoxonov test), dok za analizu srednjih vrijednosti koristio se t-test (MedCalcStatistical Software version 19. 3.1 - MedCalc Software Ltd, Ostend, Belgium; https: // www. medcalc. org; 2020).

\section{REZULTATI}

Od ukupno 100 ispitanica koje su uključene u istraživanje određeni broj ispitanica nije ispunio pojedina pitanja, što je navedeno uz svako pojedinačno pitanje. Opće značajke ispitanica i njihov socioekonomski status prikazani su u tablici 1. Najčešće zastupljene bile su bolesnice u dobi od 30 do 59 godina $(68,6 \%)$, a prosječna dob svih ispitanica izno-

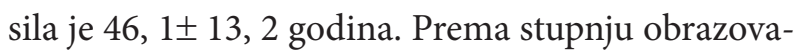
nja bilježi se najveći udio pacijentica sa završenom srednjom naobrazbom, njih (55, $6 \%)$. Ispitanice su većinom udate $(79 \%)$, a $92,8 \%$ njih je prosječnog socioekonomskog statusa.

Od ukupnog broja bolesnica koje su ispunile anketne obrasce $(n=100)$, njih $21 \%$ nije upisalo vrstu operacijskog zahvata (tablica 2). Najviše ispitanica (33\%) bilo je podvrgnuto laparoskopskom operacijskom zahvatu, a podjednako su bile zastupljene laparotomija (20\%) i vaginalne operacije (22\%). Prosječna duljina boravka u bolnici ginekološki operiranih bolesnica iznosila je 4, $6 \pm 4,1$ dana, a više od pola njih $(55,7 \%)$ boravilo je u bolnici manje od 3 dana, a raspodjela boravka u bolnici prikazana je u tablici 3.

Ocjene zadovoljstva pacijentica tijekom boravka u predoperacijskom dijelu ginekološkog odjela prikazane su u tablici 3. Sva pitanja imaju relativno visoke ocjene komunikacije s medicinskim osobljem prije operacijskog zahvata kao i u operacijskoj sali. 
Haller A, Haller A, Tomić V. Procjena zadovoljstva operiranih ginekoloških pacijentica zdravstvenom skrbi u Sveučilišnoj kliničkoj bolnici. Mostar Zdravstveni glasnik. 2021;7(1): 38-45.

Usporedbom dobivenih informacija od ginekologa o predviđenom operacijskom zahvatu i informacija o pripremi za operaciju od anesteziologa, nije nađena značajna razlika (Wilcoxonov test $=0,51$; $\mathrm{p}=0,607)$. Davanje lijekova, injekcija i drugih postupaka medicinske njege pružene od medicinskih sestara pokazuje značajnu razliku u percepciji zadovoljstva pacijentica pri čemu su medicinske sestre operacijske sale značajno bolje ocijenjene u odnosu na odjelne medicinske sestre (Wiloxonov test; $\mathrm{p}=$ 0 , 0273). Ocjene zadovoljstva pacijentica tijekom boravka u postoperacijskom dijelu ginekološkog odjela prikazani su u tablici 4. Prosječne su ocjene izuzetno visoke. Potrebno je naglasiti značajno veće ocjene za davanje informacija kod otpusta sa strane medicinskih sestara u odnosu na ginekologe (Wilcoxonov test, $\mathrm{p}=0,0398$ ). Ocjene zadovoljstva pacijentica prehranom, higijenom i pomoćnim osobljem prikazane su u tablici 5 . Sve varijable imaju izrazito visoku prosječnu ocjenu s izuzetkom kvalitete prehrane. Usporedbom broja obroka i kvalitete prehrane, potonje pitanje je je značajno slabije ocjenjeno (Wilcoxon test $=4,79 ; \mathrm{p}<0,0001$ ). Urednost i čistoća soba i sanitarnih čvorova je također visoko ocjenjena i u međusobnoj usporedbi nema značajne razlike (Wilcoxonov test, $\mathrm{p}=0,426$ ). Ukupna ocjena zadovoljstva medicinskim osobljem u Odjelu ginekologije prikazanaje u tablici 6. Prosječna ocjena zadovoljstva u svim ispitivanim kategorijama je izuzetno visoka s velikim udjelom ocjena „izvrsno“. Nema značajne razlike između pojedinih kategorija, a treba naglasiti kako je jednako zadovoljstvo liječnicima i medicinskim sestrama. Ukupna ocjena zadovoljstva pacijentica u Odjelu ginekologije prikazana je u tablici 7. Boravak u Odjelu ginekologije kako u predoperacijskom i postoperacijskom razdoblju, te ukupna kvaliteta boravka ocijenjeni su visokim prosječnim ocjenama.

Tablica 1. Opće i socioekonomske značajke ispitanica

\begin{tabular}{|c|c|c|c|}
\hline Varijabla & & Broj & $(\%)$ \\
\hline Životna dob & $20-29$ & 10 & $(11,6 \%)$ \\
\hline \multirow[t]{6}{*}{$(\mathrm{n}=86)$} & $30-39$ & 20 & $(23,3 \%)$ \\
\hline & $40-49$ & 19 & $(22,1 \%)$ \\
\hline & $50-59$ & 20 & $(23,3 \%)$ \\
\hline & $60-69$ & 14 & $(16,3 \%)$ \\
\hline & $70-79$ & 3 & $(3,5 \%)$ \\
\hline & $\mathrm{SV} \pm \mathrm{SD}($ medijan$)$ & \multicolumn{2}{|c|}{$46,1 \pm 13,2(45)$} \\
\hline Stupanj obrazovanja & Završena osnovna škola & 9 & $(9,1 \%)$ \\
\hline \multirow[t]{4}{*}{$(n=99)$} & Završena srednja škola & 55 & $(55,6 \%)$ \\
\hline & Završen preddiplomski studij & 5 & $(5,1 \%)$ \\
\hline & Završen diplomski studij & 29 & $(29,3 \%)$ \\
\hline & Završen doktorat & 1 & $(1,0 \%)$ \\
\hline Bračni status & Udata & 79 & $(79,0 \%)$ \\
\hline \multirow[t]{3}{*}{$(\mathrm{n}=100)$} & Neudata & 11 & $(11,0 \%)$ \\
\hline & Udovica & 5 & $(5,0 \%)$ \\
\hline & Razvedena & 5 & $(5,0 \%)$ \\
\hline Mjesto stanovanja & Selo & 44 & $(45,8 \%)$ \\
\hline$(n=96)$ & Grad & 52 & $(54,2 \%)$ \\
\hline Socioekonomski status & Ispodprosječan & 2 & $(2,1 \%)$ \\
\hline \multirow[t]{2}{*}{$(\mathrm{n}=97)$} & Prosječan & 90 & $(92,8 \%)$ \\
\hline & Iznadprosječan & 5 & $(5,1 \%)$ \\
\hline
\end{tabular}

$\mathrm{SV}=$ srednja vrijednost; $\mathrm{SD}=$ standardna devijacija 
Haller A, Haller A, Tomić V. Procjena zadovoljstva operiranih ginekoloških pacijentica zdravstvenom skrbi u Sveučilišnoj kliničkoj bolnici. Mostar Zdravstveni glasnik. 2021;7(1): 38-45.

Tablica 2. Vrste operacijskih zahvata kojima su ispitanice bile podvrgnute $(\mathrm{n}=100)$

\begin{tabular}{|c|c|c|}
\hline Varijabla & Broj & $(\%)$ \\
\hline Nije navedena vrsta operacijskog zahvata & 21 & $(21,0 \%)$ \\
\hline Laparotomija (rez na trbuhu) & 20 & $(20,0 \%)$ \\
\hline Laparoskopija & 33 & $(33,0 \%)$ \\
\hline Vaginalna operacija & 22 & $(22,0 \%)$ \\
\hline Histeroskopska operacija & 4 & $(4,0 \%)$ \\
\hline
\end{tabular}

Tablica 3. Zadovoljstvo pacijentica u predoperacijskom dijelu ginekološkog odjela

\begin{tabular}{|c|c|c|c|c|}
\hline $\begin{array}{c}\text { Varijabla ocjenjivanja - } \\
\text { ocjena zadovoljstva ispitanica }\end{array}$ & $\begin{array}{c}\text { Broj } \\
\text { ispitanica }\end{array}$ & $\begin{array}{c}\text { Aritmetička } \\
\text { sredina }\end{array}$ & $\begin{array}{c}\text { Standardna } \\
\text { devijacija }\end{array}$ & Medijan \\
\hline $\begin{array}{l}\text { Dobivene informacije o predviđenom operacijskom zah- } \\
\text { vatu od „ginekologa u primarnoj praksi“ }\end{array}$ & 96 & 4,7 & 0,6 & 5 \\
\hline $\begin{array}{l}\text { Dobivene informacije o predviđenom operacijskom zah- } \\
\text { vatu od „bolničkog ginekologa“ }\end{array}$ & 95 & 4,6 & 0,6 & 5 \\
\hline Komunikacija s „bolničkim“ ginekologom & 93 & 4,7 & 0,6 & 5 \\
\hline $\begin{array}{l}\text { Dobivene informacije o pripremi za operaciju od anes- } \\
\text { teziologa }\end{array}$ & 94 & 4,7 & 0,6 & 5 \\
\hline Pristup sestre prilikom pripreme za operaciju & 94 & 4,8 & 0,4 & 5 \\
\hline Komunikaciju s medicinskim sestrama & 94 & 4,8 & 0,5 & 5 \\
\hline $\begin{array}{l}\text { Načini pružanja sestrinske skrbi (davanje lijekova, injek- } \\
\text { cije, mjerenje temperature... ) }\end{array}$ & 94 & 4,8 & 0,5 & 5 \\
\hline Pristup prema Vama u operacijskoj sali & 92 & 4,9 & 0,3 & 5 \\
\hline $\begin{array}{l}\text { Način pružanja skrbi u operacijskoj sali (davanje lijekova, } \\
\text { injekcije, mjerenje temperature... ) }\end{array}$ & 92 & 4,9 & 0,4 & 5 \\
\hline
\end{tabular}

Tablica 4. Zadovoljstvo pacijentica tijekom boravka u postoperacijskom dijelu ginekološkog odjela

\begin{tabular}{|c|c|c|c|c|}
\hline Varijabla ocjenjivanja - ocjena zadovoljstva ispitanica: & $\begin{array}{c}\text { Broj } \\
\text { ispitanica }\end{array}$ & $\begin{array}{c}\text { Aritmetička } \\
\text { sredina }\end{array}$ & $\begin{array}{c}\text { Standardna } \\
\text { devijacija }\end{array}$ & Medijan \\
\hline Dobivene informacije nakon operacije od ginekologa & 92 & 4,6 & 0,7 & 5 \\
\hline Dobivene informacije prije otpusta od ginekologa & 87 & 4,7 & 0,6 & 5 \\
\hline $\begin{array}{l}\text { Načine pružanja sestrinske skrbi (davanje lijekova, injek- } \\
\text { cije, mjerenje temperature... ) }\end{array}$ & 93 & 4,8 & 0,5 & 5 \\
\hline Pomoć pri dizanju, održavanju higijene & 90 & 4,7 & 0,5 & 5 \\
\hline Brzina dolaska medicinske sestre nakon poziva zvonom & 88 & 4,8 & 0,5 & 5 \\
\hline $\begin{array}{l}\text { Osobne kvalitete medicinskih sestara (pristojnost, pošto- } \\
\text { vanje, osjetljivost, strpljivost) }\end{array}$ & 91 & 4,8 & 0,4 & 5 \\
\hline $\begin{array}{l}\text { Informacije koje ste dobili prije otpusta od medicinske } \\
\text { sestre }\end{array}$ & 85 & 4,9 & 0,4 & 5 \\
\hline
\end{tabular}

Tablica 5. Zadovoljstvo pacijentica prehranom, higijenom i pomoćnim osobljem

\begin{tabular}{lcccc}
\hline \multicolumn{1}{c}{$\begin{array}{c}\text { Varijabla ocjenjivanja - ocjena zadovoljstva } \\
\text { ispitanica }\end{array}$} & $\begin{array}{c}\text { Broj } \\
\text { ispitanica }\end{array}$ & $\begin{array}{c}\text { Aritmetička } \\
\text { sredina }\end{array}$ & $\begin{array}{c}\text { Standardna } \\
\text { devijacija }\end{array}$ & Medijan \\
\hline Odnosom tijekom upisa za prijem u Kliniku & 93 & 4,7 & 0,6 & 5 \\
Urednosti i čistoćom soba & 96 & 4,6 & 0,6 & 5 \\
Urednosti i čistoćom tuša i WC & 96 & 4,6 & 0,6 & 5 \\
Brojem obroka & 94 & 4,7 & 0,7 & 5 \\
Kvalitetom prehrane & 94 & 4,2 & 1,0 & 5 \\
Odnosom pomoćnog osoblja (spremačice) & 95 & 4,8 & 0,5 & 5 \\
Količinom primljenih informacija & 93 & 4,6 & 0,6 & 5 \\
\hline
\end{tabular}


Haller A, Haller A, Tomić V. Procjena zadovoljstva operiranih ginekoloških pacijentica zdravstvenom skrbi u Sveučilišnoj kliničkoj bolnici. Mostar Zdravstveni glasnik. 2021;7(1): 38-45.

Tablica 6. Zadovoljstvo medicinskim osobljem u Odjelu ginekologije

\begin{tabular}{lcccc}
\hline \multicolumn{1}{c}{$\begin{array}{c}\text { Varijabla ocjenjivanja } \\
\text { - ocjena zadovoljstva ispitanica za: }\end{array}$} & $\begin{array}{c}\text { Broj } \\
\text { ispitanica }\end{array}$ & $\begin{array}{c}\text { Aritmetička } \\
\text { sredina }\end{array}$ & $\begin{array}{c}\text { Standardna } \\
\text { devijacija }\end{array}$ & Medijan \\
\hline $\begin{array}{l}\text { Liječnike - ginekologe na predoperacijskom dijelu } \\
\text { Odjela }\end{array}$ & 92 & 4,8 & 0,5 & 5 \\
\hline Medicinske sestre na predoperacijskom dijelu Odjela & 92 & 4,8 & 0,4 & 5 \\
\hline Medicinske sestre na Odsjeku intenzivne njege & 90 & 4,8 & 0,4 & 5 \\
\hline Liječnike ginekologe na postoperacijskom dijelu Odjela & 91 & 4,8 & 0,5 & 5 \\
\hline Medicinske sestre na postoperacijskom dijelu Odjela & 91 & 4,8 & 0,4 & 5 \\
\hline
\end{tabular}

Tablica 7. Zadovoljstvo pacijentica tijekom boravka u Odjelu ginekologije

\begin{tabular}{lcccc}
\hline \multicolumn{1}{c}{$\begin{array}{c}\text { Varijabla ocjenjivanja - } \\
\text { ocjena zadovoljstva ispitanica za: }\end{array}$} & $\begin{array}{c}\text { Broj } \\
\text { ispitanica }\end{array}$ & $\begin{array}{c}\text { Aritmetička } \\
\text { sredina }\end{array}$ & $\begin{array}{c}\text { Standardna } \\
\text { devijacija }\end{array}$ & Medijan \\
\hline $\begin{array}{l}\text { Ukupnu kvalitetu boravka u predoperacijskom dijelu } \\
\text { Odjela }\end{array}$ & 90 & 4,6 & 0,6 & 5 \\
$\begin{array}{l}\text { Ukupnu kvalitetu boravka u postoperacijskom dijelu } \\
\text { Odjela }\end{array}$ & 90 & 4,7 & 0,5 & 5 \\
Ukupnu kvalitetu boravka u Odjelu za ginekologiju & 89 & 4,6 & 0,5 & 5 \\
\hline
\end{tabular}

\section{RASPRAVA}

Ova studija je pokazala da je ukupno zadovoljstvo pacijentica izuzetno visoko kad je u pitanju kvaliteta pruženih usluga, razina komunikacija i odnos čitavog osoblja u Odjelu ginekologije Sveučilišne kliničke bolnice Mostar. Prema podacima iz literature, visoke ocjene zadovoljstva pacijenata su ukazale da su ljubaznost, poštovanje, pažljivo slušanje i jednostavan pristup njezi medicinskih sestara najsnažniji pokretač ukupnog zadovoljstva pacijenata (2-4). Ovi aspekti zdravstvene njege visoko su ocijenjeni od stranepacijentica, u usporedbi s drugim neovisnim čimbenicima kao što su skrb liječnika, postupak prijema, fizičko okruženje i čistoća. Čimbenici zdravstvene ustanove koji mogu pogodovati pacijentima uključuju: dostupnost, kvalificirano osoblje i čistoću bolničkog okruženja. Sve to može predstavljati pozitivnu preporuku bolnicama u visoko razvijenim zemljama (5). U jednom istraživanju provedenom u Indiji zadovoljstvo pacijenata komunikacijom s liječnicima u vezi njihovogzdravstvenogproblema iskazalo je $57 \%$ ispitanika, manje nego u drugimstudijama u kojima se zadovoljstvo komunikacijom s liječnicima kretalo od $69,1 \%$ do 93, 2\% ispitanika (6-8). Dakle, zadovoljstvo komunikacijom s liječnicima uvelike varira diljem svijeta i ovisi o mnogim čimbenicima. $U$ našem istraživanju zadovoljstvo dobivenim informacijama i komunika- cijom sa strane ginekologa u predoperacijskom i postoperacijskom dijelu ginekološkog odjela ocjenjeni su visokim prosječnim ocjenama. Također, visok je udio ocjena „izvrsno“ i kreće se za pojedina pitanja između 70 i $90 \%$. U literaturi se navode studije koje pokazuju i $100 \%$ zadovoljstva pacijenata s dobivenom ljubaznošću i poštovanjem te posvećenim vremenom liječnika (6). Čistoća potiče zadovoljstvo među korisnicima bolničkih usluga i čini razliku između bolnica. U ovome istraživanju izuzetno su dobre prosječne ocjene u pogledu urednosti i čistoće bolesničkih soba, urednosti i čistoće tuša i WCa, dok je prosječna ocjena kvalitete prehrane slabije ocjenjena u odnosu na broj obroka. Usporedbom rezultata dobivenih u ovom istraživanju s drugim istraživanjima naglašava raznoliki doživljaj čistoće i urednosti prostora, što zahtijeva dodatno ispitivanje. Štoviše, navedena problematika uočava se i u drugim studijama, posebno u onima koje dolaze iz zemalja trećeg svijeta. Zanimljiv je podatak jednog istraživanja u Indiji gdje je većina ispitanika bila zadovoljna čistoćom koja je primijećena u bolnici $(88 \%)$, ali čak $66 \%$ ispitanika je promatralo bolnički ambijent mirno, bez davanja svojih komentara i sugestija, što otvara pitanje pasivnog ili aktivnog učešća pacijenta u doživljavanju i kritičkom sagledavanju bolničkog okruženja (6). Komunikacijske vještine između zdravstvenih radnika i pacijenata 
predstavlja izuzetno važnu odrednicu u oblikovanju zadovoljstva korisnika medicinskih usluga (9). Ipak, potrebno je pokušati definirati zadovoljstvo pacijenata na temelju više pokazatelja kvalitete zdravstvene usluge i načina na koji pacijenti razvijaju svoje zadovoljstvo zdravstvenim uslugama (9). Ako je zadovoljstvo pacijenata primarno pitanje zdravstvenih usluga, prvi korak je uspostavljanje ili jačanje edukacije studenata medicine, zdravstvenih studija i zdravstvenih radnika na radnom mjestu. Spomenuta edukacija uključuje komunikacijske i empatičke vještine (10). Uporno ocjenjivanje kompetencija i međuljudskih vještina zdravstvenih djelatnika je ključno za određivanje prioriteta kako bi se zadovoljstvo pacijenata moglo učinkovitije povećati edukacijom i poticajima zdravstvenih radnika (11).

Duljina boravka u bolničkoj ustanovi može uzrokovati promjene u rezultatima zadovoljstva. Pacijenti koji kraće borave u bolnicama naginju boljem ocjenjivanju, u odnosu na one koji su hospitalizirani dulje vrijeme(12). Također, treba uzeti u obzir razlog hospitalizacije, težinu stanja i bolesti kao i prognozu same bolesti. U ovome istraživanju nije opažena razlika u ukupnom zadovoljstvu obzirom na pojedine vrste operacijskog zahvata. Zanimljivo je opažanje da ispitanice koje nisu ispunile vrstu operacijskog zahvata (16 ispitanica) je iskazalo ocjenu „izvrsno“ u 62, 5 \% slučaja, što je usporedivo sa ostalim kategorijama operacijskog zahvata.

U analizi dviju postavki - zadovoljstva pacijenta i spremnosti za povratak $\mathrm{u}$ istu ustanovu identificirani su važni čimbenici predikcije ukupnog zadovoljstva pacijenata - individualizirana medicinsku njega, ljubaznost liječnika, ishod liječenja i organizacija otpusta (13). Rezultati studije sugeriraju da zadovoljstvo pacijenata i spremnost za povratak pružatelju usluga ne odražavaju iste koncepte. Iako aspekti usluge poput kvalitete hrane utječu na ocjenu zadovoljstva, oni ne povećavaju vjerojatnost da pacijenti odaberu istu bolnicu u slučaju ponovnog liječenja. Komunikacija između pacijenata i liječnika vrlo je važna. Smatra se da se navedeni prediktori oba koncepta mogu izmijeniti od strane zdravstvenih djelatnika i trebalo bi ih usmjeriti na poboljšanje zadovoljstva pacijenata i povećanje vjerojatnosti da se pacijenti vrate „svom liječniku“. Ipak za sveobu- hvatno razumijevanje zadovoljstva pacijenta potreban je dublji pristup u analizi tog višeslojnog i složenog procesa. Upravo iz tog razloga švicarski autori nakon provedene analize na 54. 686 hospitaliziranih pacijenata su predložili multidimenzionalni model s više razina (14). Prvo sepretpostavlja da osnovu čini pet dimenzija: komunikacija s pacijentom, komunikacija s obitelji, rješavanje strahova i zabrinutosti, priprema za otpust iz bolnice i zadovoljstvo pacijenta. Drugo, hipotezirani model uključuje pozitivne odnose između sve četiri dimenzije komunikacije, $s$ jedne strane, i zadovoljstva pacijenata, s druge strane. Unutar dimenzija komunikacije pretpostavljena je komunikacija s pacijentom kao glavni čimbenik za sve ostale dimenzije, pa je time pozitivno povezana s ostala tri oblika komunikacije. Rezultati su pokazali prisutnost čimbenika zadovoljstva s pet stavki koji kombiniraju opće zadovoljstvo, namjeru za povratkom, percepciju da su tretirani s poštovanjem i dostojanstvom, savjetovanje i terapiju boli. Analize su također otkrile da su čimbenici komunikacije strukturirani prema cilju komunikacije (pacijent ili obitelj) i sadržaju komunikacije (rješavanje strahova i zabrinutosti ili pripreme za otpust iz bolnice). Štoviše, dimenzija komunikacije i zadovoljstva logično su povezane jedna s drugom. Ovi rezultati naglašavaju potrebu za multidimenzionalnim pristupom analizi zadovoljstva pacijenata.

Potrebno je naglasiti ograničenja ovog istraživanja. Upitnik je konstruiran zaovo istraživanje i nema potrebnu validaciju u širem značenju. Provedeno istraživanje ima ograničenje u tumačenju rezultata radi nemogućnosti usporedbe sa sličnim ispitivanjima obzirom da se radi o prvom istraživanju takve vrste među pacijenticama hospitaliziranim u Odjelu ginekologije SKB Mostar koje su bile podvrgnutejednom od ginekoloških operacijskih zahvata. Obzirom na ograničeni broj ispitanica nije bilo moguće provoditi dodatne usporedbe unutar pojedinih podskupina i provesti dodatnu analizu ocjena zadovoljstva.

\section{ZAKLJUČAK}

Ovo istraživanje predstavlja referentnu vrijednost za provođenje daljnjih istraživanja o zadovoljstvu ginekoloških pacijentica. Dobivene visoke prosječ- 
ne ocjene $\mathrm{u}$ svim ispitanim kategorijama $\mathrm{u}$ što su uključene komunikacija i dobivanje informacija od sudionika provođenja ginekološkog operativnog liječenja (ginekolozi, anesteziolozi, medicinske sestre Odjela ginekologije i operacijske sale) postavlja visoke standarde koje u budućnosti treba održati. Istovremeno visoke ocjene $\mathrm{u}$ pogledu urednosti $\mathrm{i}$ čistoće, kvalitete prehrane i odnosa nemedicinskog osoblja je zavidan doseg provođenja dobre organizacije u širem pogledu. Visoke ocjene zadovoljstva pacijentica predstavljaju obvezu nastavka njegovanja komunikacijskih vještina ukupnog medicinskog i nemedicinskog osoblja.

\section{LITERATURA}

1. Ashrafun L, Uddin MJ. Factors determining inpatient satisfaction with hospital care in Bangladesh. Int J Pharm Res Health Sci 2011; 7(6): 15-24.

2. Tonio S, Joerg K, Joachim K. Determinants of patient satisfaction: a study among 39 hospitals in an in-patient setting in Germany. Int J Qual Health Care 2011; 23(5): 503-509.

3. Forough R, Mohammad E, Hamid H. Nurse caring in Iran and its relationship with patient satisfaction. Aust J Adv Nurs 2007; 26(2): 7584.

4. Choi KS, Lee H, Kim C, Lee S. The service quality dimensions and patient satisfaction relationships in South Korea: comparisons across gender, age and types of service. J Serv Market 2006; 19(3): 140-149.

5. Iliyasu Z, Abubakar IS, Abubakar S, Lawan UM, Gajida AU. Patients' satisfaction with services obtained from Aminu Kano Teaching Hospital, Kano, Northern Nigeria. Niger J Clin Pract 2010; 13: 371-8.

6. Shekhawat S, Garg S, Jain D, Sharma U. Inpatient satisfaction level survey at a tertiary care hospital. Int J Res Med Sci 2017; 5: 240-4.
7. Peerasak L, Surasak B, Pattanwadi U. Patient satisfaction on health service at the family medicine learning centers. Chaing Mai Med Bull 2004; 43: 67-76.

8. Acharya JP, Acharya I. A study on compliance and behavioral responses of patients in an outpatient clinic. Indian J Community Med 2003; 28(1): 19-25.

9. Sanchez-Piedra CA, Prado-Galbarro FJ, Garcia-Perez S, Santamera AS. Factors associated with patient satisfaction with primary care in Europe: results from the EUprimecare project. Qual Prim Care 2014; 22: 147-55.

10. Roter D, Rosenbaum J, de Negri B, Renaud D, DiPrete-Brown L, Hernandez O. The effects of a continuing medical education programme in interpersonal communication skills on doctor practice and patient satisfaction in Trinidad and Tobago. Med Educ 1998; 32: 181-9.

11. Crow r, Gage H, Hampson S, Hart J, Kimber A, Storey L, Thomas H. The measurement of satisfaction with healthcare: implications for practice from a systematic review of the literature. Health Technol Assess 2002; 6: $1-244$.

12. Tokunaga J, Imanaka Y. Influence of length of stay on patient satisfaction with hospital care in Japan. Int J Qual Health Care 2002; 14: 493-502.

13. Schoenfelder T, Schaal T, Klewer J, Kugler J. Patient satisfaction and willingness to return to the provider among women undergoing gynecological surgery. Arch Gynecol Obstet2014; 290(4): 683-90.

14. Pelletier D, Gree-Demers I, Collerette P, Heberer M. Modeling the communication satisfaction relationship in hospital patients. SAGE Open Med 2019; 29(7): 205032119847924. 


\title{
ASSESSMENT OF SATISFACTION WITH HEALTH CARE IN POST-OPERATIVE GYNECOLOGY PATIENTS AT THE UNIVERSITY CLINICAL HOSPITAL MOSTAR
}

\author{
Albert Haller ${ }^{1}$, Adriana Haller ${ }^{1}$, Vajdana Tomić ${ }^{1,2,3}$ \\ ${ }^{1}$ School of Medicine University of Mostar \\ ${ }^{2}$ Department of Gynecology and Obstetrics University Clinical Hospital Mostar \\ ${ }^{3}$ Faculty of Health Studies University of Mostar \\ Bijeli brijeg b. b. 88000 Mostar, Bosnia and Herzegovina
}

\begin{abstract}
INTRODUCTION: Today, the quality of the health care is measured with the help of two parameters, patient outcomes and patient satisfaction.

OBJECTIVE: The objective of this study is to investigate the level of satisfaction with health care in post-operative gynecology patients.

METHODS: This cross-sectional study of patient satisfaction was conducted at the gynecology ward of the Department of Gynecology and Obstetrics of the University Clinical Hospital Mostar by an anonymous survey using a questionnaire designed exclusively for this study. The study included a total of 100 patients who underwent gynecological surgery.

RESULTS: All preoperative and postoperative categories at the gynecology ward, including communication with gynecologists, anesthesiologists and nurse were rated with higher than the average score of 4 . 5. The study group had a relatively short hospital stay with an average of 4.6 days. More than $70 \%$ of patients were hospitalized for up to 6 days. Order and cleanliness of were rated with a high average score of 4. 6; and the attitude of service staff is at high-level (average score 4. 6). CONCLUSION: High satisfaction scores represent an obligation for continuing to nurture the communication skills of the overall medical and non-medical staff. The current study is a starting point for further research on patient satisfaction at the gynecology department.

Key words: patient satisfaction, health care, gynecology, University Clinical Hospital Mostar

Correspondence: Professor Vajdana Tomić, MD, PhD

E-mail: vajdana. tomic@fzs.sum.ba
\end{abstract}

